\title{
Awareness of and intention to use an online sexually transmitted and blood-borne infection testing service among gay and bisexual men in British Columbia, two years after implementation
}

\author{
Joshun Dulai ${ }^{1,2} \cdot$ Travis Salway ${ }^{2,3} \cdot$ Kimberly Thomson ${ }^{2,4} \cdot$ Devon Haag $^{2} \cdot$ Nathan Lachowsky $^{5}$ - Daniel Grace ${ }^{6}$. \\ Joshua Edward ${ }^{7}$. Troy Grennan ${ }^{2,8} \cdot$ Terry Trussler $^{9} \cdot$ Mark Gilbert $^{2,3}$
}

Received: 16 October 2019 / Accepted: 13 April 2020 / Published online: 16 June 2020

(C) The Author(s) 2020

\begin{abstract}
Objectives This study assessed gay, bisexual, and other men who have sex with men's (GBMSM) awareness of and intention to use GetCheckedOnline, an online sexually transmitted and blood-borne infection (STBBI) testing service.

Methods A cross-sectional study was conducted two years after launch among GBMSM > 18 years of age in British Columbia, Canada. Participants were recruited through community venues, clinics, websites, and apps.

Results Of 1272 participants, 32\% were aware of GetCheckedOnline. Gay identity, regularly testing at an STBBI clinic, being out to one's healthcare provider, attending GBMSM community venues, and frequent social media use were associated with awareness. Among participants who were aware but had not used GetCheckedOnline, knowing GetCheckedOnline users, using social media, not knowing where else to test, and not wanting to see a doctor were associated with intention to use GetCheckedOnline.

Conclusion Early promotion of GetCheckedOnline resulted in greater awareness among those connected to GBMSM.
\end{abstract}

\section{Résumé}

Objectifs Évaluer chez les hommes gais, bisexuels et les hommes ayant des relations sexuelles avec des hommes (gbHARSAH) la connaissance de GetCheckedOnline, un service de dépistage en ligne des infections transmissibles sexuellement et par le sang (ITSS), et l'intention d'utiliser ce service.

Méthode Deux ans après le lancement du service, une étude transversale a été menée auprès d'hommes gbHARSAH de plus de 18 ans en Colombie-Britannique, au Canada. Les participants ont été recrutés dans les milieux associatifs, les cliniques, sur des sites Web et au moyen d'applications.

Résultats Sur 1272 participants, $32 \%$ connaissaient GetCheckedOnline. L'identité gaie, le dépistage périodique à une clinique d'ITSS, le fait d'avoir dévoilé son orientation sexuelle à son dispensateur de soins de santé, la fréquentation de milieux associatifs pour hommes gbHARSAH et l'utilisation fréquente des médias sociaux étaient associés à la connaissance du service. Chez les participants qui connaissaient GetCheckedOnline mais qui ne l'avaient pas utilisé, le fait de connaître des utilisateurs de GetCheckedOnline, l'utilisation des médias sociaux, le fait de ne pas savoir où se faire tester ailleurs et le fait de ne pas vouloir voir un médecin étaient associés à l'intention d'utiliser GetCheckedOnline.

Conclusion La promotion précoce de GetCheckedOnline a rehaussé la visibilité de ce service dans les milieux en lien avec les hommes gbHARSAH.

Keywords Men who have sex with men · Gay and bisexual men · Sexually transmitted and blood-borne infection testing · Online sexual health services

Mots-clés Hommes ayant des relations sexuelles avec des hommes · Hommes gais et hommes bisexuels $\cdot$ Dépistage des infections transmissibles sexuellement et par le sang · Services de santé sexuelle en ligne

Mark Gilbert

mark.gilbert@bccdc.ca

Extended author information available on the last page of the article 


\section{Introduction}

Gay, bisexual, and other men who have sex with men (GBMSM) are disproportionately affected by sexually transmitted and blood-borne infections (STBBI; British Columbia Centre for Disease Control 2018a, b) and face distinct barriers to STBBI testing (Gilbert et al. 2013; Hottes et al. 2012). Decreasing barriers to testing may reduce the impact and onward transmission of STBBIs in this population by providing prompt diagnosis and treatment (i.e., secondary prevention). Online services allow individuals to receive STBBI tests without having to visit a clinic and thus are one promising method for reducing barriers and increasing testing among GBMSM. Online STBBI testing services vary in process, although typically clients answer screening questions over the Internet instead of in person with a doctor or nurse. They then either order a self-testing kit online and return their specimens in the mail, or download a laboratory requisition and provide specimens on-site in a non-clinic-based setting. Clients receive their results online (Gibbs et al. 2018; Greenland et al. 2011; Koekenbier et al. 2008; Loos et al. 2016; Lorimer and McDaid 2013; Platteau et al. 2015), over the phone (Chai et al. 2010; Gaydos et al. 2006), or through text message (Woodhall et al. 2012).

In this context, the British Columbia Centre for Disease Control (BCCDC) launched GetCheckedOnline (GCO) in September 2014 as an alternative to in-person testing options already in place in the province. The development of GCO has been described in detail elsewhere (Gilbert et al. 2016). In brief, GCO clients first create an online account using a promotional code. To request online STBBI tests, clients answer a series of sexual history questions to determine the appropriate tests to recommend. Based on these recommendations, clients then confirm the tests they want and print a lab requisition. They then go to a participating laboratory location to collect and submit samples for HIV, syphilis, gonorrhea, chlamydia, and/or hepatitis $\mathrm{C}$ testing; clients receive their results within 1 to 2 weeks. If any results are positive, or if there are issues with the sample (e.g., sample container damaged), results are not available online, and a nurse contacts the client directly to arrange treatment or retesting. Test results that are negative for STBBIs are provided online. GCO was initially promoted to GBMSM in the Greater Vancouver area in Canada through a promotion campaign from April to August 2015 with promotion on gay websites and apps and in community venues accessed by GBMSM (Gilbert et al. 2019).

Our team previously surveyed an online sample of Canadian GBMSM in 2011/2012 and found that $72 \%$ intended to use a hypothetical Internet-based testing service, if available (Gilbert et al. 2013). While measures of intention for health behaviour are useful in preliminary stages of intervention planning, intention is an imperfect proxy for behaviour (Todd et al. 2016); thus, follow-up studies are needed to determine uptake. More specifically, it is important from an implementation perspective to understand how awareness of the intervention has diffused through a population (in this case, GBMSM in British Columbia (BC)) and what additional factors should be emphasized in future promotion of the service (e.g., among those aware of but unengaged with the service). Moreover, fundamental causes theory predicts that socially disadvantaged groups stand to miss opportunities to use new interventions, owing to lower access to social or material resources, including those related to healthcare interventions (Phelan et al. 2010). In this context, it is additionally important to measure social differences in awareness of and intention to use new interventions, such as online STBBI testing.

Therefore, the primary objectives of this study were to assess awareness of GCO two years after implementation and intention to use GCO among those aware of the service, and to assess whether GCO was addressing or had the potential to address health inequities that exist within subgroups of GBMSM in relation to uptake of online STBBI testing. Our overarching goal was to use this evidence to inform future promotion of GCO and related online STBBI interventions.

\section{Methods and materials}

\section{Eligibility criteria and recruitment}

This report is based on a cross-sectional survey of selfidentified GBMSM, 18 years of age or older and living in BC. Data collection began on July 29, 2016, and ended December 18, 2016 ( $~ 5$ months), which was $23-28$ months after GCO launched. No personally identifiable information was collected, and participation was voluntary. For this study, venue-based (non-probability) sampling was used to recruit GBMSM. However, to try to obtain as diverse a sample of this community as possible, a multi-pronged sampling strategy was devised to recruit GBMSM through three venue categories: GBMSM community venues, STBBI clinics targeting GBMSM, and GBMSM online/mobile sites/apps. Paperbased surveys were distributed at pride events, festivals, and GBMSM bars (hereafter, "community venues") in the Greater Vancouver region during the early weeks of data collection. Paper survey data were also collected at local STBBI clinics operated by the Health Initiative for Men (HIM), a community organization that was created to address the health needs of GBMSM living in Metro Vancouver (hereafter, "HIM clinics"). HIM operates five sexual health centres where GBMSM can make appointments or walk in to get STBBI testing, access HIV non-occupational post-exposure prophylaxis (PEP), and receive treatment for STBBIs. Surveys were administered at all five Metro Vancouver locations.

Finally, an online version of the survey was distributed through six different online and mobile app channels: 
Craigslist; Scruff; Squirt; Hornet; boosts on the HIM Facebook page; as well as social media platforms, websites, and e-mail lists of community organizations located within the province that cater to GBMSM (hereafter, grouped as "online" venues). The online survey was created using the program FluidSurveys.

\section{Survey development}

The survey instrument was developed by the study team at the BCCDC with input from other researchers and community partners. The survey was pilot tested with a small group of volunteers and revised before being used to collect data from participants. Questions were adapted from past or current surveys of GBMSM or about GCO, with new questions created for our specific purpose. The Diffusions of Innovations (DOI) theoretical framework was used in designing the survey and its questions (Rogers 2005). This theory seeks to explain how novel ideas or interventions spread along various modes of communication over time within a population. Berwick suggests that there are three important factors that determine how quickly an innovation is spread: (a) perception of the innovation, (b) characteristics of the people who adopt the innovation or fail to do so, and (c) contextual factors (Berwick 2003). Accordingly, the survey included the following three outcomes: awareness, use, and intention to use GCO. In addition, we measured the following domains corresponding to DOI predictor variables: perceived benefits and drawbacks of GCO (DOI category: perception of the innovation); usual STBBI testing location and satisfaction with said location, specific barriers to STBBI testing, and knowledge of GCO users (DOI category: contextual factors); and STBBI testing history; sexual orientation disclosure to healthcare providers; number of sexual partners within the last year; technology use; attendance at specific GBMSM community venues in the past year; and demographic information (DOI category: characteristics of the adopters).

\section{Outcomes of interest}

Survey items were selected to measure awareness of and intention to use GCO among GBMSM living in BC. Awareness was assessed by providing a brief description of GCO and asking the question: "Before today did you know about GetCheckedOnline?" Intention to use GCO was assessed with the question: "How unlikely or likely is it that you will get tested through GetCheckedOnline in the future?" Five response options were offered: "Very likely", "Likely", "Neither likely nor unlikely", "Unlikely", and "Very unlikely". For both univariate and multivariable analyses, this item was recoded as the binary variable "intention to use GCO" with those who reported being "Very Likely" or "Likely" categorized as those who "intend to use" GCO and all other responses were recoded as those who "do not intend to use" GCO.

\section{Analysis plan}

To identify potential explanatory variables associated with awareness of and intention to use GCO among those aware of the service, a conceptual causal diagram was created, informed by DOI theory (see Fig. 1; Berwick 2003; Rogers 2005). A continuous score representing mobile app and website use termed "social media app score" was created by counting the number of apps and websites used by the participant. Two sets of binary logistic regression analyses were conducted. First, we evaluated associations between explanatory variables and awareness of GCO in the full sample. Second, we evaluated associations between explanatory variables and intention to use GCO, restricted to those who were aware of GCO but had not yet used it. These analyses were applied in the interest of targeting future GCO promotion including strategies for reaching GBMSM unaware of GCO, and identifying messages that may increase intention to use among GBMSM who have heard about GCO but have not yet used the service. Univariate odds ratios (uOR) and adjusted odds ratios (aOR) were estimated, and 95\% confidence intervals excluding 1 were considered statistically significant. All hypothesized explanatory variables - identified using the causal diagram - were entered into the multivariable model simultaneously to avoid omission of negatively confounded variables that may be missed with forward/stepwise selection procedures (Vittinghoff et al. 2012). In interpreting results, we emphasize $\mathrm{uOR}$ rather than aOR because unadjusted measures are more relevant for our goal of informing future promotion of GCO; i.e., adjusted measures may obscure meaningful differences in awareness of and intention to use GCO, due to confounding. All data were analyzed using SPSS Version 21. This study was approved by the Ethics Board at the University of British Columbia.

\section{Results}

In total, 1272 GBMSM participated in this study. The proportion of men recruited from each venue were as follows: $24.1 \%$ (307/1272) from community venues, $23.8 \%$ (303/1272) from HIM clinics, and $52.0 \%(662 / 1272)$ from online venues. Sample demographic characteristics are presented in Table 1 . The majority of study participants were under the age of $40(53.5 \%, 646 / 1272)$ : $26.2 \%(316 / 1207)$ were 18 29 , and $27.3 \%(330 / 1207)$ were $30-39$. In total, $78.1 \%$ (987/ 1264) identified as gay. Most of the study participants lived within the city of Vancouver $(55.3 \%, 704 / 1272)$ with another $24.5 \%$ (312/1272) living in the surrounding cities comprising Metro Vancouver, and 12.3\% (156/1272) living in other parts 


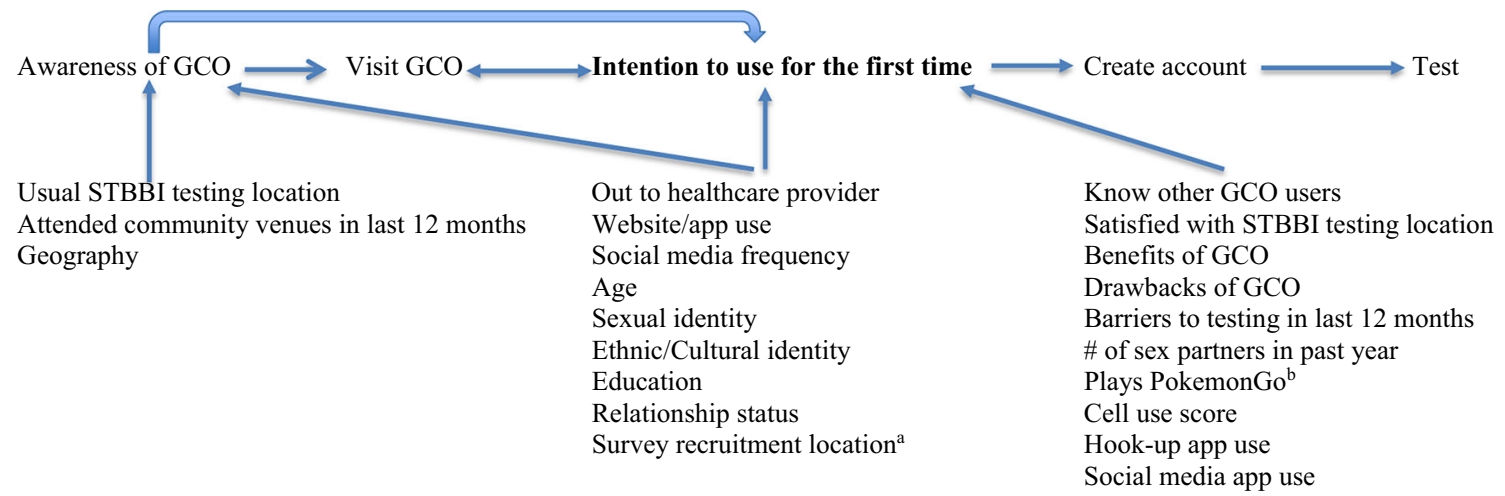

a. Survey recruitment location may influence awareness and intention as promotion for GCO occurred in some of these locations

b. "Plays PokemonGo" was included in our survey as a proxy measure of early adopters based on DOI

Fig. 1 A conceptual causal diagram of the hypothesized relationships for variables of interest. ${ }^{\text {a }}$ Survey recruitment location may influence awareness and intention as promotion for GCO occurred in some of these locations. "Plays PokemonGo" was included in our survey as a proxy measure of early adopters based on DOI of the province. Most study participants identified as White (73.0\%, 917/1256), and East Asian (9.0\%, 113/1256) and Latino/Hispanic $(5.9 \%, 74 / 1256)$ were the most frequently reported racialized minority identities. Indigenous participants comprised $2.9 \%(37 / 1256)$ of the sample. The overall study sample was highly educated, with $67.4 \%$ (848/1258) of participants having completed some form of post-secondary education. A majority of participants were single (52.4\%, 657/ 1255)

Regarding the study outcome measures, $32.4 \%$ (411/1268) of participants reported being aware of GCO (see Table 1). Among those aware of GCO, 44.8\% (174/388) had visited the website, $17.5 \%$ had created an account (68/388), and $11.3 \%$ (44/388) had tested; thus, overall, $3.5 \%$ of GBMSM surveyed (44/1268) had tested for STBBIs using GCO. Among those aware of the service and who had not yet tested through GCO, $45.2 \%(166 / 367)$ reported intending to do so. Among those who had used the service $(n=44), 88.6 \%$ reported intending to use the service again.

Factors associated with awareness of GCO are shown in Table 2. Being out to one's healthcare provider (uOR 2.29 (1.67-3.14)), website/app use (uOR 1.36 (1.07-1.73)), and frequent social media use (uOR 1.84 (1.29-2.62)) were all associated with greater odds, and bisexual identity (uOR $0.67(0.47-0.96))$ with lower odds, of awareness of GCO with $\mathrm{CI}$ that excluded $\mathrm{uOR}$ of 1 . Participants who usually tested at a public health STBBI clinic (uOR 1.57 (1.20-2.06)), youth clinic (uOR 2.54 (1.09-5.93)), or HIM clinic (uOR 2.44 (1.91-3.11)) had higher odds of awareness, while those who usually tested through a family doctor or hospital (uOR 0.39 $(0.18-0.85))$, and those who had no usual testing location (uOR $0.27(0.12-0.65)$ ) or history of testing (uOR 0.29
(0.14-0.61)) had lower odds of awareness, with CI that excluded uOR of 1 . All community venue variables were also associated with awareness with the exception of the bathhouse variable.

The following variables remained positively associated with GCO awareness in multivariable analysis, with aOR CI excluding 1: being out to one's healthcare provider (aOR 1.92 (1.18-3.10)), frequent social media use (aOR 1.87 (1.103.17)), having visited an LGBT organization in the last 12 months (aOR $1.59(1.14-2.21)$ ), and usual testing at a public health STI clinic (aOR 1.57 (1.09-2.27)) or HIM clinic (aOR 1.64 (1.13-2.37)). Having tested at a hospital emergency room was negatively associated with GCO awareness (aOR 0.28 (0.10-0.84)).

Factors associated with intention to use GCO among those who were aware of the service but had not tested through GCO are shown in Table 3. Knowing other GCO users, using social media apps, not knowing where to test in person, not wanting to see a doctor, and all perceived benefits of the service, except having a physical exam, were associated with higher odds of intention to use, with uOR CI excluding 1. Knowing other GCO users (aOR 2.47 (1.02-5.97)) and the perceived benefit of GCO of saving time (aOR 2.62 (1.30 5.27)) remained associated with intention to use and statistically significant in multivariable analyses.

\section{Discussion}

Two years after the implementation of a novel online STBBI testing service in British Columbia, Canada, we assessed awareness of GCO and intention to use among those aware 
Table 1 Characteristics of GBMSM who participated in a survey about Internet-based STBBI testing in BC, 2016

\begin{tabular}{|c|c|c|}
\hline \multicolumn{2}{|l|}{ metrinetas } & \multirow{2}{*}{ Variables } \\
\hline Variables & $n / N(\%)$ & \\
\hline \multicolumn{2}{|l|}{ Age (birth year) } & Usual STBBI testing location \\
\hline $18-29(<1986)$ & $316 / 1207(26.2 \%)$ & Family physician \\
\hline $30-39(1986-1977)$ & $330 / 1207(27.3 \%)$ & Walk-in medical clinic \\
\hline $40-49(1976-1967)$ & $208 / 1207(17.2 \%)$ & Public health STBBI clinic \\
\hline $50-59(1966-1957)$ & 205/1207 (17.0\%) & Youth clinic \\
\hline $60+(1956+)$ & $148 / 1207(12.3 \%)$ & Health Initiative for Men (HIM) clinic ${ }^{\mathrm{a}}$ \\
\hline \multicolumn{2}{|l|}{ Sexual identity } & At a hospital or emergency room \\
\hline Gay (homosexual) & $987 / 1264(78.1 \%)$ & Through GetCheckedOnline \\
\hline Bi (bisexual) & $202 / 1264(16.0 \%)$ & Other \\
\hline Straight (heterosexual) & $60 / 1264(4.7 \%)$ & No usual place \\
\hline Queer & $59 / 1264(4.7 \%)$ & I've never been tested for STBBIs \\
\hline Two-spirit & $12 / 1264(0.9 \%)$ & Satisfied with current STBBI testing location \\
\hline Other & $14 / 1264(1.1 \%)$ & \\
\hline Prefer not to say & $13 / 1264(1.0 \%)$ & Barriers to STBBI testing in the last 12 months \\
\hline \multicolumn{2}{|l|}{ Region } & None of the above \\
\hline Vancouver & $704 / 1272(55.3 \%)$ & The wait was too long \\
\hline Suburban Vancouver & $312 / 1272(24.5 \%)$ & Needed an appointment \\
\hline Rest of BC & $156 / 1272(12.3 \%)$ & The clinic wasn't open when I could test \\
\hline Invalid postal code & $100 / 1272(7.9 \%)$ & Other \\
\hline \multicolumn{2}{|l|}{ Ethnic/cultural identity } & Couldn't get anonymous testing \\
\hline Indigenous (First Nations, Inuit, Métis) & $37 / 1256(2.9 \%)$ & The clinic was too far away \\
\hline African & $8 / 1256(0.6 \%)$ & Didn't want to see a doctor or nurse \\
\hline East Asian & $113 / 1256(9.0 \%)$ & Didn't know where to go \\
\hline South Asian & $31 / 1256(2.5 \%)$ & I do not like needles \\
\hline Southeast Asian & $44 / 1256(3.5 \%)$ & Out to healthcare provider \\
\hline Caribbean & $12 / 1256(1.0 \%)$ & Yes \\
\hline Latino/Hispanic & $74 / 1256(5.9 \%)$ & No \\
\hline Middle Eastern & $24 / 1256(1.9 \%)$ & Not sure \\
\hline Pacific Islander & $16 / 1256(1.3 \%)$ & Do not have a healthcare provider or \\
\hline White/Caucasian & $917 / 1256(73.0 \%)$ & have not seen one \\
\hline Other & $33 / 1256(2.6 \%)$ & Cell phone use \\
\hline Prefer not to say & $8 / 1256(0.6 \%)$ & Textıng \\
\hline \multicolumn{2}{|l|}{ Education } & \multirow[t]{2}{*}{ Surfing the Internet } \\
\hline Some high school & $19 / 1258(1.5 \%)$ & \\
\hline High school & $110 / 1258(8.7 \%)$ & Using other apps (navigation, games, etc.) \\
\hline Some college/university & $281 / 1258(22.3 \%)$ & Meeting guys (Grindr, Scruff, etc.) \\
\hline College & $184 / 1258(14.6 \%)$ & Playing Pokémon Go \\
\hline University degree (BA, BSc, etc.) & $429 / 1258(34.1 \%)$ & I have a cell phone but do not do any \\
\hline Graduate degree (MA, MBA, etc.) & $192 / 1258(15.3 \%)$ & of the above \\
\hline Doctorate $(\mathrm{PhD}, \mathrm{MD}$, etc.) & $43 / 1258(3.4 \%)$ & I do not have a cell phone \\
\hline \multicolumn{2}{|l|}{ Relationship status } & Website/app use \\
\hline Single & $657 / 1255(52.4 \%)$ & Facebook \\
\hline Married to a man & $125 / 1255(10.0 \%)$ & YouTube \\
\hline Partnered with a man but not married & $298 / 1255(23.7 \%)$ & Grindr \\
\hline Separated, divorced, or widowed from a man & $21 / 1255(1.7 \%)$ & Instagram \\
\hline Married to a woman & $62 / 1255(4.9 \%)$ & Craigslist \\
\hline Partnered with a woman but not married & $35 / / 1255(2.8 \%)$ & Squirt \\
\hline Separated, divorced, or widowed from a woman & $35 / 1255(2.8 \%)$ & Scruff \\
\hline
\end{tabular}

$n / N(\%)$

$22 / 1255(1.8 \%)$

$439 / 1267(34.6 \%)$

$211 / 1267(16.7 \%)$

$290 / 1267(22.9 \%)$

$22 / 1267(1.7 \%)$

$457 / 1267(36.1 \%)$

$49 / 1267(3.9 \%)$

$21 / 1267(1.7 \%)$

$80 / 1267(6.3 \%)$

$51 / 1267(4.0 \%)$

$63 / 1267(5.0 \%)$

$1001 / 1247$

$(80.3 \%)$

$610 / 1173(52.0 \%)$

$191 / 1173(16.3 \%)$

$174 / 1173(14.8 \%)$

$170 / 1173(14.5 \%)$

$86 / 1173(7.3 \%)$

$85 / 1173(7.2 \%)$

$84 / 1173(7.2 \%)$

$76 / 1173(6.5 \%)$

$73 / 1173(6.2 \%)$

$42 / 1173(3.6 \%)$

$906 / 1255(72.2 \%)$

$242 / 1255(19.0 \%)$

$34 / 1255(2.7 \%)$

$73 / 1255(5.7 \%)$

$1171 / 1260$

(92.9\%)

$1084 / 1260$

(86.0\%)

$915 / 1260(72.6 \%)$

$794 / 1260(62.4 \%)$

$267 / 1260(21.2 \%)$

$34 / 1260(2.7 \%)$

$30 / 1272(2.4 \%)$

$865 / 1223(70.7 \%)$

$793 / 1223$ (64.8\%)

$565 / 1223(46.2 \%)$

$544 / 1223(44.5 \%)$

461/1223 (37.7\%)

401/1223 (32.8\%)

$374 / 1223(30.6 \%)$ 
Table 1 (continued)

\begin{tabular}{lc}
\hline Variables & $n / N(\%)$ \\
\hline Twitter & $341 / 1223(27.9 \%)$ \\
Snapchat & $321 / 1223(26.2 \%)$ \\
Hornet & $177 / 1223(14.5 \%)$ \\
Manhunt & $158 / 1223(12.9 \%)$ \\
Growlr & $110 / 1223(9.0 \%)$ \\
Jack'd & $108 / 1223(8.8 \%)$ \\
BarebackRT & $101 / 1223(8.3 \%)$ \\
Frequent social media use ${ }^{b}$ & $1068 / 1255$ \\
& $(85.1 \%)$
\end{tabular}

Attended community venues in the last 12 months (versus not)

Gay bar, pub, or nightclub

$713 / 1005(70.9 \%)$

Bathhouse

LGBT organization

Gay social, recreational, or sporting group

Vancouver pride festival or event

Other community events for LGBT individuals

Number of sex partners in the last 12 months

0
1
$2-5$
$6-9$
$10+$

Survey recruitment location

Community venues

HIM clinics

Online

Aware of GCO

Unaware of GCO

How heard about GCO $^{b}$

Ad on a website or phone app

Printed material (posters, brochures, etc.)

Social media (Facebook, Twitter, etc.)

From friends

From a physician, nurse, or clinic

From someone at a community organization

Other

News media (TV, newspaper, Xtra, etc.)

From a boyfriend/partner

Know any other GCO Users ${ }^{\mathrm{c}}$

Visited GCO website ${ }^{\mathrm{c}}$

Created an account with $\mathrm{GCO}^{\mathrm{c}}$

Tested through $\mathrm{GCO}^{\mathrm{c}}$

Intend to use GCO

Intention to use GCO among those aware and who have not tested through GCO

Benefits of GCO

Testing without waiting for an appointment

Getting test results online

Saves time

$662 / 1272(52.0 \%)$

$411 / 1268(32.4 \%)$

$857 / 1268(67.6 \%)$

$130 / 391(33.2 \%)$

$84 / 391(21.5 \%)$

$81 / 391(20.7 \%)$

$70 / 391(17.9 \%)$

$59 / 391(15.1 \%)$

$54 / 391(13.8 \%)$

$54 / 391(13.8 \%)$

$43 / 391(11.0 \%)$

$14 / 391(3.6 \%)$

$84 / 391(21.5 \%)$

$174 / 388(44.8 \%)$

$68 / 388(17.5 \%)$

$44 / 388(11.3 \%)$

$605 / 1248(48.5 \%)$

$166 / 367(45.2 \%)$

$631 / 1255(50.3 \%)$

$572 / 1255(45.6 \%)$

$471 / 1255(37.5 \%)$
Table 1 (continued)

\begin{tabular}{ll}
\hline Variables & $n / N(\%)$ \\
\hline Easier to go to a lab than a clinic & $416 / 1255(33.1 \%)$ \\
Do not need to see a doctor or nurse & $415 / 1255(33.1 \%)$ \\
Testing when the clinic is full & $372 / 1255(29.6 \%)$ \\
Do not need to talk about my sex life & $368 / 1255(29.3 \%)$ \\
Not sure & $243 / 1255(19.4 \%)$ \\
Do not need to get a physical exam & $223 / 1255(17.8 \%)$ \\
I see no benefits & $76 / 1255(6.1 \%)$ \\
Other & $42 / 1255(3.3 \%)$ \\
Drawbacks of GCO & \\
Not speaking with a doctor or nurse & $480 / 1247(38.5 \%)$ \\
Unclear how it works & $324 / 1247(26.0 \%)$ \\
Worried about the privacy of my online & $244 / 1247(19.6 \%)$ \\
information & \\
Not sure & $217 / 1247(17.4 \%)$ \\
I see no drawbacks & $177 / 1247(14.2 \%)$ \\
Need to print the lab form & $172 / 1247(13.8 \%)$ \\
Need to have a promo code to sign up & $111 / 1247(8.9 \%)$ \\
Not easy to get to a lab & $99 / 1247(7.9 \%)$ \\
Not comfortable going to a lab & $86 / 1247(6.9 \%)$ \\
Low trust in the service & $70 / 1247(5.5 \%)$ \\
Other & $62 / 1247(5.0 \%)$ \\
Getting test results online & $59 / 1247(4.7 \%)$ \\
\hline
\end{tabular}

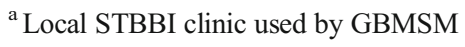

b "Frequent" defined as daily use or using social media a few times a week

${ }^{\mathrm{c}}$ Among those aware of the service among a large sample of GBMSM. Overall, $32.4 \%$ of our sample were aware of GCO. Among those aware who had not yet used the service, $45.2 \%$ of GBMSM reported intending to test through GCO in the future. Factors associated with awareness included gay identity, usually testing at an STBBI clinic, being out to a healthcare provider, attending GBMSM venues, and frequent social media use. These findings are largely consistent with the GCO promotional strategy which targeted gay men during the first year post-launch that advertised online and in clinics (Gilbert et al. 2019). Intention to use GCO was associated with knowing other GCO users, using social media, not knowing where else to test, and not wanting to see a doctor. This is one of the first studies to examine intention to use among persons aware of a recently launched online STBBI testing service in the context of other testing options, rather than intention to use a hypothetical model (Gilbert et al. 2013; Hottes et al. 2012) or currently available online testing methods more broadly (Koekenbier et al. 2008; Platteau et al. 2015). This is also the first study to examine intention to use an existing online service within Canada. Below, we offer an interpretation of the results, 
Table 2 Characteristics associated with awareness of GetCheckedOnline in a survey of GBMSM in BC, $2016(n=1272)$

\begin{tabular}{|c|c|c|c|c|}
\hline Variables & $\begin{array}{l}\text { Aware } \\
n / N(\%)\end{array}$ & $\begin{array}{l}\text { Unaware } \\
n / N(\%)\end{array}$ & $\begin{array}{l}\text { uOR } \\
(95 \% \text { CI) }\end{array}$ & $\begin{array}{l}\mathrm{aOR} \\
(95 \% \mathrm{CI})\end{array}$ \\
\hline Intend to use GCO & $205 / 605(33.9 \%)$ & $400 / 605(66.1 \%)$ & NA & NA \\
\hline \multicolumn{5}{|l|}{ Usual STBBI testing location $^{\mathrm{a}}$} \\
\hline Family physician & $123 / 436(28.2 \%)$ & $313 / 436(71.8 \%)$ & $0.74(0.57-0.95)$ & $0.75(0.51-1.10)$ \\
\hline Walk-in medical clinic & $64 / 211(30.3 \%)$ & $147 / 211(69.7 \%)$ & $0.89(0.65-1.22)$ & $0.77(0.49-1.19)$ \\
\hline Public health STI clinic & $117 / 290(40.3 \%)$ & $173 / 290(59.7 \%)$ & $1.57(1.20-2.06)$ & $1.57(1.09-2.27)$ \\
\hline Youth clinic & $12 / 22(54.5 \%)$ & $10 / 22(45.5 \%)$ & $2.54(1.09-5.93)$ & $1.81(0.66-4.98)$ \\
\hline Health Initiative for Men (HIM) clinic & $206 / 456(45.2 \%)$ & $250 / 456(54.8 \%)$ & $2.44(1.91-3.11)$ & $1.64(1.13-2.37)$ \\
\hline At a hospital or emergency room & $8 / 49(16.3 \%)$ & $41 / 49(83.7 \%)$ & $0.39(0.18-0.85)$ & $0.28(0.10-0.84)$ \\
\hline Other & $31 / 80(38.8 \%)$ & $49 / 80(61.3 \%)$ & $1.34(0.84-2.14)$ & $1.23(0.69-2.21)$ \\
\hline No usual place & $6 / 50(12.0 \%)$ & $44 / 50(88.0 \%)$ & $0.27(0.12-0.65)$ & $0.40(0.11-1.43)$ \\
\hline I've never been tested for HIV/STIs & $8 / 63(12.7 \%)$ & $55 / 63(87.3 \%)$ & $0.29(0.14-0.61)$ & $1.97(0.60-6.44)$ \\
\hline Out to healthcare provider & $331 / 903(36.7 \%)$ & $572 / 903(63.3 \%)$ & $2.29(1.67-3.14)$ & $1.92(1.18-3.10)$ \\
\hline Website/app use & $248 / 700(35.4 \%)$ & $452 / 700(64.6 \%)$ & $1.36(1.07-1.73)$ & $1.29(0.92-1.80)$ \\
\hline Frequent social media use & $366 / 1065(34.4 \%)$ & $699 / 1065(65.6 \%)$ & $1.84(1.29-2.62)$ & $1.87(1.10-3.17)$ \\
\hline \multicolumn{5}{|c|}{ Attended community venues in last 12 months (versus not) ${ }^{\mathrm{a}}$} \\
\hline Gay bar, pub, or nightclub & $269 / 710(37.9 \%)$ & $441 / 710(62.1 \%)$ & $1.58(1.17-2.13)$ & $1.19(0.82-1.72)$ \\
\hline Bathhouse & $81 / 204(39.7 \%)$ & $123 / 204(60.3 \%)$ & $1.29(0.94-1.77)$ & $1.18(0.81-1.72)$ \\
\hline LGBT organization (HIM, Qmunity, etc.) & $178 / 373(47.7 \%)$ & $195 / 373(52.3 \%)$ & $2.42(1.85-3.17)$ & $1.59(1.14-2.21)$ \\
\hline $\begin{array}{l}\text { Gay social, recreational, or sporting group; } \\
\text { Vancouver pride festival or event; other } \\
\text { community events for LGBT individuals }\end{array}$ & $339 / 966(35.1 \%)$ & $627 / 966(64.9 \%)$ & $1.73(1.29-2.32)$ & $0.57(0.23-1.44)$ \\
\hline \multicolumn{5}{|l|}{ Age } \\
\hline Continuous, years & Median: 35 (SD:13.7) & Median: 39 (SD: 14.2) & $0.99(0.98-1.00)$ & $1.00(0.98-1.01)$ \\
\hline $18-29(<1986)$ & $114 / 316(36.1 \%)$ & $202 / 316(63.9 \%)$ & & \\
\hline $30-39$ (1986-1977) & $118 / 329(35.9 \%)$ & $211 / 329(64.1 \%)$ & & \\
\hline $40-49(1976-1967)$ & $65 / 207(31.4 \%)$ & $142 / 207(68.6 \%)$ & & \\
\hline $50-59(1966-1957)$ & $53 / 204(26.0 \%)$ & $151 / 204(74.0 \%)$ & & \\
\hline $60+(1956+)$ & $45 / 148(30.4 \%)$ & $103 / 148(69.6 \%)$ & & \\
\hline \multicolumn{5}{|l|}{ Sexual identity } \\
\hline Gay (homosexual) & $313 / 925(33.8 \%)$ & $612 / 925(66.2 \%)$ & REF & REF \\
\hline Bi (bisexual) & $47 / 184(25.5 \%)$ & $137 / 184(74.5 \%)$ & $0.67(0.47-0.96)$ & $0.86(0.48-1.53)$ \\
\hline Other sexual orientations & $45 / 138(32.6 \%)$ & $93 / 138(67.4 \%)$ & $0.95(0.65-1.39)$ & $1.70(0.97-3.01)$ \\
\hline \multicolumn{5}{|l|}{ Region } \\
\hline Vancouver & $346 / 1013(34.2 \%)$ & $667 / 1013(65.8 \%)$ & REF & REF \\
\hline Suburban Vancouver & $37 / 156(23.7 \%)$ & $119 / 156(76.3 \%)$ & $1.31(0.83-2.08)$ & $0.83(0.48-1.46)$ \\
\hline Rest of BC & $28 / 99(28.3 \%)$ & 71/99 (71.7\%) & $0.79(0.45-1.40)$ & $1.10(0.46-2.66)$ \\
\hline \multicolumn{5}{|l|}{ Ethnic/cultural identity } \\
\hline White & $286 / 872(32.8 \%)$ & $586 / 872(67.2 \%)$ & REF & REF \\
\hline Racialized minorities & $116 / 372(31.2 \%)$ & $256 / 372(68.8 \%)$ & $0.93(0.72-1.21)$ & $0.81(0.57-1.16)$ \\
\hline \multicolumn{5}{|l|}{ Education } \\
\hline$<$ College & $123 / 409(30.1 \%)$ & $286 / 409(69.9 \%)$ & REF & REF \\
\hline College+ & $288 / 859(33.5 \%)$ & $571 / 859(66.5 \%)$ & $1.17(0.91-1.51)$ & $1.08(0.77-1.51)$ \\
\hline \multicolumn{5}{|l|}{ Relationship status } \\
\hline Single & 206/655 (31.5\%) & $449 / 655(68.5 \%)$ & REF & REF \\
\hline Partnered with a man & $157 / 443(35.4 \%)$ & $286 / 443(64.6 \%)$ & $1.12(0.93-1.54)$ & $1.04(0.75-1.44)$ \\
\hline Partnered with a woman & $34 / 131(26.0 \%)$ & $97 / 131(74.0 \%)$ & $0.76(0.50-1.17)$ & $1.04(0.48-2.26)$ \\
\hline
\end{tabular}


Table 2 (continued)

\begin{tabular}{lllll}
\hline Variables & $\begin{array}{l}\text { Aware } \\
n / N(\%)\end{array}$ & $\begin{array}{l}\text { Unaware } \\
n / N(\%)\end{array}$ & $\begin{array}{l}\text { uOR } \\
(95 \% \mathrm{CI})\end{array}$ & $\begin{array}{l}\text { aOR } \\
(95 \% \mathrm{CI})\end{array}$ \\
\hline Community venues & $90 / 304(29.6 \%)$ & $214 / 304(70.4 \%)$ & REF & REF \\
HIM clinics & $111 / 303(36.6 \%)$ & $192 / 303(63.4 \%)$ & $1.38(0.98-1.93)$ & $1.18(0.76-1.81)$ \\
Online & $210 / 661(68.2 \%)$ & $451 / 661(68.2 \%)$ & $1.11(0.82-1.49)$ & $1.01(0.69-1.50)$ \\
\hline
\end{tabular}

Category counts may not add to 1272 due to missing data

${ }^{a}$ Question asked participants to select all that apply; thus, options were analyzed as binary variable

specifically attending to how they will inform promotion of the GCO service in the future.

While our estimated uptake of GCO among GBMSM at the time of data collection was $3 \%$ of GBMSM in $\mathrm{BC}$, our finding that $45.2 \%$ of survey respondents who were aware of GCO intended to use the service in the future suggests there are large opportunities for future promotion and expansion of the service. Our results specifically highlight opportunities to equitably target future promotion of GCO to those who were less likely to be aware of the service. This includes bisexual men, those who are not out to healthcare providers, those without a history of STBBI testing, and those who are less connected to GBMSM community venues. These groups are less likely to be reached through promotions targeting gay men, and thus may require using novel and creative outlets, such as support groups for bisexual individuals and network-based promotion and recruitment strategies (Hartman 2011). Reaching GBMSM who are less connected to the gay community may also mean using more general promotional strategies, such as Google Ad campaigns. Reaching these individuals will require creative solutions; however, it is clearly feasible to reach them, given that they participated in the survey. Future studies may include qualitative research with these specific groups to understand their opinion of online testing services like GCO. One result of such an approach may be more equitable provision of online sexual health services to those who otherwise miss out on the opportunity for prompt diagnoses and treatment of STBBIs.

Our results additionally suggest promotional messages that are likely to resonate with those who are aware of and intend to use GCO in the future. These messages may be most effective if they emphasize the convenience and efficiency of the service (e.g., saving time), and the ability to get tested without seeing a doctor or a nurse. However, given that our sample of survey participants who were aware of GCO underrepresents bisexual men and those disconnected from gay community venues and STBBI testing, additional work will be needed to understand which perceived benefits are most important to these underrepresented groups in particular.

This study is limited by its cross-sectional design. We cannot assess temporality and infer the direction of causation between variables examined; for example, we cannot know if participants were aware of GCO before attending the venues where GCO was advertised. We relied upon a non-probability sample of GBMSM for this study; thus, participants may not be representative of the larger GBMSM population. However, 31.8\% (14/44) of survey respondents who used GCO were under the age of 30 compared with $39.5 \%$ (185/468) of all GBMSM users from September 2014 to December 2016 (data not shown). We attempted to mitigate this limitation by recruiting our sample from different sites, including community venues, GBMSM-specific STBBI testing clinics, and websites and apps used by GBMSM. A final limitation is that all information collected for this study was self-reported. Both recall and social desirability bias may influence the responses participants gave. We tried to mitigate for this by enabling participants to fill out the survey on their own when at community venues, having it provided by clinic receptionists instead of study staff in HIM clinics, and making the survey available online. With regard to recall bias, we limited the recall period of questions to within the past year.

\section{Conclusion}

Future research should include more studies on the impact online STBBI testing is having on overall STBBI prevalence and incidence within GBMSM, other target populations, or among all users. Given our findings that bisexual men, those not out to healthcare providers, and those who do not test at STBBI clinics were less likely to be aware of GCO, we further recommend additional research into how best to adapt interventions (or promotional efforts) to reach these subpopulations. Studies are also needed to assess awareness and reach of GCO and other online STBBI interventions in populations 
Table 3 Analyses with "Intention to use GCO" as the outcome restricted to those aware of the service and who have not tested through GCO $(n=367)$

\begin{tabular}{|c|c|c|c|}
\hline Predictor variables & $n / N(\%)^{\mathrm{a}}$ & uOR $(95 \% \mathrm{CI})$ & $\mathrm{aOR}(95 \% \mathrm{CI})$ \\
\hline Know other GCO users & $36 / 58(62.1 \%)$ & $2.18(1.22-3.89)$ & $2.47(1.02-5.97)$ \\
\hline \multicolumn{4}{|l|}{ Satisfied with STBBI testing location } \\
\hline Unsatisfied & $28 / 49(57.1 \%)$ & REF & REF \\
\hline Satisfied & $138 / 318(43.4 \%)$ & $0.58(0.31-1.06)$ & $1.33(0.46-3.81)$ \\
\hline Benefits: do not need to talk about my sex life & $50 / 85(58.8 \%)$ & $2.00(1.22-3.28)$ & $1.67(0.69-4.01)$ \\
\hline Benefits: do not need to get a physical exam & $29 / 54(53.7 \%)$ & $1.46(0.82-2.61)$ & $1.05(0.35-3.15)$ \\
\hline Benefits: easier to go to a lab than a clinic & $72 / 114(63.2 \%)$ & $2.84(1.79-4.49)$ & $2.40(1.11-5.21)$ \\
\hline Benefits: getting test results online & $89 / 158(56.3 \%)$ & $2.16(1.41-3.30)$ & $0.81(0.39-1.70)$ \\
\hline Benefits: testing without waiting for an appointment & $101 / 182(55.5 \%)$ & $2.24(1.47-3.42)$ & $1.80(0.82-3.94)$ \\
\hline Benefits: testing when the clinic is full & $62 / 115(53.9 \%)$ & $1.62(1.04-2.54)$ & $1.22(0.53-2.77)$ \\
\hline Benefits: do not need to see a doctor or nurse & $63 / 111(56.8 \%)$ & $1.90(1.21-2.99)$ & $0.73(0.32-1.69)$ \\
\hline Benefits: saves time & $79 / 130(60.8 \%)$ & $2.61(1.68-4.06)$ & $2.62(1.30-5.27)$ \\
\hline Drawbacks: not speaking with a doctor or nurse & $65 / 163(39.9 \%)$ & $0.68(0.45-1.04)$ & $1.12(0.57-2.20)$ \\
\hline Drawbacks: getting test results online & $5 / 11(45.5 \%)$ & $1.02(0.31-3.40)$ & $0.44(0.06-2.98)$ \\
\hline Drawbacks: need to print the lab form & $27 / 67(40.3 \%)$ & $0.79(0.46-1.35)$ & $0.58(0.24-1.37)$ \\
\hline Drawbacks: not easy to get to a lab & $12 / 33(36.4 \%)$ & $0.67(0.32-1.41)$ & $0.78(0.25-2.39)$ \\
\hline Drawbacks: not comfortable going to a lab & $10 / 34(29.4 \%)$ & $0.48(0.22-1.03)$ & $0.57(0.18-1.75)$ \\
\hline Drawbacks: low trust in the service & $5 / 19(26.3 \%)$ & $0.42(0.15-1.19)$ & $0.66(0.13-3.25)$ \\
\hline Drawbacks: worried about the privacy of my online information & $24 / 63(38.1 \%)$ & $0.71(0.41-1.24)$ & $0.96(0.37-2.46)$ \\
\hline Drawbacks: need to have a promo code to sign up & $20 / 34(58.8 \%)$ & $1.85(0.90-3.79)$ & $1.70(0.51-5.65)$ \\
\hline Testing barrier: did not know where to go & $14 / 19(73.7 \%)$ & $3.69(1.30-10.48)$ & $1.94(0.40-9.52)$ \\
\hline Testing barrier: needed an appointment & $27 / 51(52.9 \%)$ & $1.47(0.81-2.66)$ & $0.97(0.38-2.51)$ \\
\hline Testing barrier: the wait was too long & $33 / 64(51.6 \%)$ & $1.39(0.81-2.40)$ & $0.91(0.36-2.30)$ \\
\hline Testing barrier: the clinic was too far away & $12 / 20(60.0 \%)$ & $1.92(0.76-4.81)$ & $2.21(0.44-11.08)$ \\
\hline Testing barrier: the clinic wasn't open when I could test & $29 / 59(49.2 \%)$ & $1.23(0.70-2.16)$ & $0.76(0.27-2.16)$ \\
\hline Testing barrier: did not want to see a doctor or nurse & $11 / 13(84.6 \%)$ & $7.21(1.57-33.02)$ & $8.28(0.73-93.42)$ \\
\hline Testing barrier: I do not like needles & $6 / 9(66.7 \%)$ & $2.52(0.62-10.24)$ & $1.86(0.17-20.57)$ \\
\hline Testing barrier: could not get anonymous testing & $9 / 15(60.0 \%)$ & $1.90(0.66-5.45)$ & $1.61(0.27-9.69)$ \\
\hline \multicolumn{4}{|l|}{ Out to healthcare provider } \\
\hline Not out to healthcare provider & $37 / 72(51.4 \%)$ & REF & REF \\
\hline Out to healthcare provider & $129 / 295(43.7 \%)$ & $0.74(0.44-1.23)$ & $0.96(0.34-2.72)$ \\
\hline No. of sex partners in past year & Median: 6 (SD: 27.1) & $1.00(0.99-1.01)$ & $1.00(0.98-1.01)$ \\
\hline Plays PokemonGo (a popular app in 2016) & $44 / 94(46.8 \%)$ & $1.08(0.67-1.72)$ & $0.90(0.40-2.03)$ \\
\hline Cell use score & & $1.21(0.97-1.50)$ & $1.19(0.79-1.79)$ \\
\hline Hook-up app use & $89 / 196(45.4 \%)$ & $1.02(0.67-1.53)$ & $1.15(0.54-2.42)$ \\
\hline Social media app score & & $1.18(1.09-1.27)$ & $1.01(0.79-1.29)$ \\
\hline \multicolumn{4}{|l|}{ Social media frequency } \\
\hline Infrequent use & $14 / 41(34.1 \%)$ & REF & REF \\
\hline Frequent use & $152 / 326(46.6 \%)$ & $1.69(0.85-3.33)$ & $1.74(0.58-2.42)$ \\
\hline Age (no. of years) & Median: 35 (SD: 13.8) & $1.00(0.98-1.01)$ & $1.01(0.97-1.04)$ \\
\hline \multicolumn{4}{|l|}{ Sexual identity } \\
\hline Gay & $127 / 284(44.7 \%)$ & REF & REF \\
\hline Bisexual & $20 / 40(50.0 \%)$ & $1.24(0.64-2.40)$ & $0.72(0.20-2.61)$ \\
\hline Other sexual orientations & $16 / 37(43.2 \%)$ & $0.94(0.47-1.88)$ & $0.45(0.13-1.60)$ \\
\hline \multicolumn{4}{|l|}{ Ethnicity/cultural identity } \\
\hline White & $113 / 253(44.7 \%)$ & REF & REF \\
\hline Racialized minorities & $48 / 105(45.7 \%)$ & $1.04(0.66-1.65)$ & $1.02(0.46-2.25)$ \\
\hline \multicolumn{4}{|l|}{ Education: college+ } \\
\hline$<$ College & $51 / 108(47.2 \%)$ & REF & REF \\
\hline
\end{tabular}


Table 3 (continued)

\begin{tabular}{llll}
\hline Predictor variables & $n / N(\%)^{\mathrm{a}}$ & uOR $(95 \% \mathrm{CI})$ & $\mathrm{aOR}(95 \% \mathrm{CI})$ \\
\hline College+ & $115 / 259(44.4 \%)$ & $0.89(0.57-1.40)$ & $1.02(0.52-1.99)$ \\
Relationship status & & & \\
$\quad$ Single & $184 / 354(52.0 \%)$ & $\mathrm{REF}$ & $\mathrm{R}$ \\
Partnered with a man & $142 / 354(40.1 \%)$ & $1.08(0.49-2.40)$ & $0.62(0.31-1.23)$ \\
Partnered with a woman & $28 / 354(7.9 \%)$ & $0.80(0.35-1.80)$ & $0.63(0.13-3.08)$ \\
Survey recruitment location & & & REF \\
Community venues & $43 / 86(50.0 \%)$ & REF & $0.75(0.42-1.33)$ \\
HIM clinics & $45 / 105(42.9 \%)$ & $0.80(0.48-1.34)$ & $0.65(0.28-1.50)$ \\
Online & $78 / 176(44.3 \%)$ & & $0.43-2.42)$ \\
\hline
\end{tabular}

${ }^{\mathrm{a}} n / N=$ number who intend to use/number who do and do not intend to use

other than GBMSM. Finally, we recognize that there is a paucity of research on the health system impacts of online testing services that are also worthy of attention, including how these are integrated with and affect face-to-face testing services, and their cost-effectiveness.

Funding information Funding for this study was provided by the Canadian Institutes of Health Research (PHE-318068). NJL is supported by a Michael Smith Foundation for Health Research Scholar Award (no. 16863). DG is a Canada Research Chair in Sexual and Gender Minority Health and is also supported by an Early Researcher Award from the Ontario Ministry of Research, Innovation and Science. KCT is supported by a Canadian Institutes of Health Research Fellowship award.

\section{Compliance with ethical standards}

Conflict of interest The authors declare that they have no conflict of interest.

Open Access This article is licensed under a Creative Commons Attribution 4.0 International License, which permits use, sharing, adaptation, distribution and reproduction in any medium or format, as long as you give appropriate credit to the original author(s) and the source, provide a link to the Creative Commons licence, and indicate if changes were made. The images or other third party material in this article are included in the article's Creative Commons licence, unless indicated otherwise in a credit line to the material. If material is not included in the article's Creative Commons licence and your intended use is not permitted by statutory regulation or exceeds the permitted use, you will need to obtain permission directly from the copyright holder. To view a copy of this licence, visit http://creativecommons.org/licenses/by/4.0/.

\section{References}

Berwick, D. M. (2003). Disseminating innovations in health care. JAMA, 289(15), 1969-1975.

British Columbia Centre for Disease Control. (2018a). HIV in British Columbia: annual surveillance report 2016. http://www.bccdc.ca/ resource-gallery/Documents/Statistics\%20and\%20Research/
Statistics\%20and\%20Reports/STI/HIV_Annual_Report_2016.pdf. Accessed January 19, 2019.

British Columbia Centre for Disease Control. (2018b). STI in British Columbia: annual surveillance report 2016. http://www.bccdc.ca/ resource-gallery/Documents/Statistics\%20and\%20Research/ Statistics\%20and\%20Reports/STI/STI_Annual_Report_2016.pdf. Accessed January 19, 2019.

Chai, S. J., Aumakhan, B., Barnes, M., Jett-Goheen, M., Quinn, N., Agreda, P., et al. (2010). Internet-based screening for sexually transmitted infections to reach nonclinic populations in the community: risk factors for infection in men. Sexually Transmitted Diseases, 37(12), 756-763.

Gaydos, C. A., Dwyer, K., Barnes, M., Rizzo-Price, P. A., Wood, B. J., Flemming, T., et al. (2006). Internet-based screening for chlamydia trachomatis to reach non-clinic populations with mailed selfadministered vaginal swabs. Sexually Transmitted Diseases, 33(7), 451-457.

Gibbs, J., Aicken, C. R., Sutcliffe, L. J., Gkatzidou, V., Tickle, L. J., Hone, K., et al. (2018). Mixed-methods evaluation of a novel online STI results service. Sexually Transmitted Infections, 94(8), 622624.

Gilbert, M., Hottes, T. S., Kerr, T., Taylor, D., Fairley, C. K., Lester, R., et al. (2013). Factors associated with intention to use internet-based testing for sexually transmitted infections among men who have sex with men. Journal of Medical Internet Research, 15(11), e254.

Gilbert, M., Haag, D., Hottes, T. S., Bondyra, M., Elliot, E., Chabot, C., et al. (2016). Get checked... where? The development of a comprehensive, integrated internet-based testing program for sexually transmitted and blood-borne infections in British Columbia, Canada. JMIR Research Protocols, 5(3), e186.

Gilbert, M., Salway, T., Haag, D., Kwag, M., Edward, J., Bondyra, M., et al. (2019). Assessing the impact of a social marketing campaign on program outcomes for users of an internet-based testing service for sexually transmitted and blood-borne infections: observational study. Journal of Medical Internet Research, 21(1), e11291.

Greenland, K. E., Op de Coul, E. L. M., van Bergen, J. E. A. M., Brouwers, E. E. H. G., Fennema, H. J. S. A., Götz, H. M., et al. (2011). Acceptability of the internet-based chlamydia screening implementation in the Netherlands and insights into nonresponse. Sexually Transmitted Diseases, 38(6), 467-474.

Hartman, J. E. (2011). Finding a needle in a haystack: methods for sampling in the bisexual community. Journal of Bisexuality, 11(1), 64 74.

Hottes, T. S., Farrell, J., Bondyra, M., Haag, D., Shoveller, J., \& Gilbert, M. (2012). Internet-based HIV and sexually transmitted infection testing in British Columbia, Canada: opinions and expectations of 
prospective clients. Journal of Medical Internet Research, 14(2), e41.

Koekenbier, R. H., Davidovich, U., van Leent, E. J. M., Thiesbrummel, H. F., \& Fennema, H. S. A. (2008). Online-mediated syphilis testing: feasibility, efficacy, and usage. Sexually Transmitted Diseases, 35(8), 764-769.

Loos, J., Manirankunda, L., Platteau, T., Albers, L., Fransen, K., Vermoesen, T., et al. (2016). Acceptability of a community-based outreach HIV-testing intervention using oral fluid collection devices and web-based HIV test result collection among Sub-Saharan African migrants: a mixed-method study. JMIR Public Health and Surveillance, 2(2), e33.

Lorimer, K., \& McDaid, L. (2013). Young men's views toward the barriers and facilitators of internet-based chlamydia trachomatis screening: qualitative study. Journal of Medical Internet Research, 15(12), e265.

Phelan, J. C., Link, B. G., \& Tehranifar, P. (2010). Social conditions as fundamental causes of health inequalities: theory, evidence, and policy implications. Journal of Health and Social Behavior, 51(Suppl), S28-S40.
Platteau, T., Fransen, K., Apers, L., Kenyon, C., Albers, L., Vermoesen, T., et al. (2015). Swab2know: an HIV-testing strategy using oral fluid samples and online communication of test results for men who have sex with men in Belgium. Journal of Medical Internet Research, 17(9), e213.

Rogers, E. M. (2005). Diffusion of innovations. New York: Free Press.

Todd, J., Kothe, E., Mullan, B., \& Monds, L. (2016). Reasoned versus reactive prediction of behaviour: a meta-analysis of the prototype willingness model. Health Psychology Review, 10(1), 1-24.

Vittinghoff, E., Glidden, D. V., Shiboski, S. C., \& McCulloch, C. E. (2012). Regression methods in biostatistics: linear, logistic, survival, and repeated measures models. New York: Springer-Verlag //www.springer.com/gp/book/9781461413523. Accessed January 19, 2019.

Woodhall, S. C., Sile, B., Talebi, A., Nardone, A., \& Baraitser, P. (2012). Internet testing for chlamydia trachomatis in England, 2006 to 2010. BMC Public Health, 12, 1095.

Publisher's note Springer Nature remains neutral with regard to jurisdictional claims in published maps and institutional affiliations.

\section{Affiliations}

\section{Joshun Dulai ${ }^{1,2} \cdot$ Travis Salway $^{2,3} \cdot$ Kimberly Thomson $^{2,4} \cdot$ Devon Haag $^{2} \cdot$ Nathan Lachowsky $^{5} \cdot$ Daniel Grace $^{6}$.

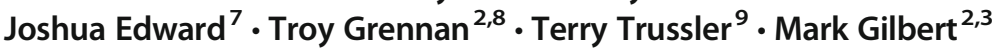

1 Department of Sociomedical Sciences, Mailman School of Public Health, Columbia University, 722 West 168th Street, New York, NY 10032, USA

2 British Columbia Centre for Disease Control, 655 West 12th Avenue, Vancouver, BC V5Z 4R4, Canada

3 Faculty of Health Sciences, Simon Fraser University, 888 University Drive, Burnaby, BC V5A 1S6, Canada

4 School of Population and Public Health, University of British Columbia, 2206 East Mall, Vancouver, BC V6T 1Z3, Canada

5 School of Public Health \& Social Policy, University of Victoria, 3800 Finnerty Road, Victoria, BC V8P 5C2, Canada
6 Social \& Behavioural Health Sciences Division, Dalla Lana School of Public Health, University of Toronto, 155 College Street, Toronto, ON M5T 3M7, Canada

7 Health Initiative for Men, 1033 Davie Street, Vancouver, BC V6E 1M5, Canada

8 Division of Infectious Diseases, Faculty of Medicine, University of British Columbia, 2194 Health Sciences Mall, Vancouver, BC V6T 1Z3, Canada

9 Community-Based Research Centre, 808 Nelson Street, Vancouver, BC V6Z 2H2, Canada 